\title{
Yoga after Traumatic Brain Injury: Changes in Emotional Regulation and Health-Related Quality of Life in a Case- Study
}

\begin{abstract}
Purpose: The purpose of this study was to analyze changes in emotional regulation and health-related quality of life (HRQOL) following a yoga intervention for three participants with traumatic brain injury (TBI). Yoga was utilized as a modality to improve HRQOL and emotional regulation.
\end{abstract}

Methods: A mixed method design was used to analyze changes in emotional regulation and HRQOL. Participants completed an eight-week yoga intervention and assessments were completed before and after the intervention. Outcome measures included the Difficulty in Emotional Regulation Scale (DERS) and Quality of Life after Brain Injury Scale (QOLIBRI, both are reliable and valid after TBI. The Change in score (percent change) were calculated for data from both assessments. Semi-structured interviews were completed, data were transcribed, and qualitative data were analyzed with a focus on emotional regulation and HRQOL.

Results: On average, the three participants had a 16\% improvement in DERS scores and 6\% improvement in QOLIBRI scores following the yoga intervention. Analysis of the qualitative data indicate that participants identified improvements related to emotional regulation in the mind-body connection, peaceful and calm feelings, concentration and focus, and self-control. In relation to HRQOL participants noted social changes, physical changes leading to life changes, confidence to do things and self-development.

Conclusion: Yoga is a potential intervention to address emotional regulation and HRQOL for individuals with chronic TBI. Emotional regulation and HRQOL are two important factors affected post-TBI that through this study were impacted by yoga as a focused mind-body intervention.

Keywords

Emotional Regulation; Health-related Quality of Life; Traumatic Brain Injury; Yoga; Mind-Body Interventions

Research Article
Volume 8 Issue 1 - 2017
Laura A Grimm OTR ${ }^{1 *}$, Marieke Van
Puymbroeck CTRS ${ }^{2}$ Kristine K Miller PT ${ }^{3}$,
Thomas Fisher FAOTA ${ }^{4}$ and Arlene A Schmid
OTR ${ }^{1}$
${ }^{1}$ Department of Occupational Therapy, Colorado State
University, USA
${ }^{2}$ Department of Parks, Recreation, and Tourism Management,
Clemson University, USA
${ }^{3}$ Department of Physical Therapy, Indiana University School of
Health and Rehabilitation Sciences, USA
${ }^{4}$ Vera Z. Dwyer College of Health Sciences, Indiana University
South Bend, USA of Health and Rehabilitation Sciences, USA
*Corresponding author: Laura Grimm, Colorado State
University, College of Health and Human Sciences,
Department of Occupational Therapy, Fort Collins, Co, Tel:
315-373-9168; Fax: $970-491-6290 ;$
Email: Igrimm1@ colostate.edu
Received: May 19, 2017 | Published: July 24, 2017

Abbreviations: TBI: Traumatic Brain Injury; HRQOL: HealthRelated Quality of Life; MMSE: Mini Mental Status Exam; DERS: Difficulty in Emotion Regulation Scale; RYT: Registered Yoga Therapist

\section{Introduction}

A traumatic brain injury (TBI) is a form of acquired brain injury, resulting from damage caused by an external force to the head [1]. The injury can be penetrating or non-penetrating, creating an open or closed head injury. In 2010, it was estimated that 2.2 million emergency room visits in the United States resulted in a TBI diagnosis [2]. Over three million Americans are living with a residual disability because of a TBI $[3,4]$. The effects of TBI permeate the individual's lifespan, potentially creating low life satisfaction and high activity limitations [5]. Just five years following injury, of those who received TBI-specific rehabilitation, $60 \%$ had either died or experienced functional decline [6]. Due to alterations in brain function, a TBI can result in residual impairments in physical, emotional, cognitive, social, and daily functioning across the lifespan [7].

The impact of a health condition impairment on an individual's perception of function is known as health-related quality of life (HRQOL) [8]. TBI is associated with multiple long-term impairments in HRQOL [9], potentially affecting functioning in physical, emotional, cognitive, and social domains [10]. Individuals with TBI often develop poor coping strategies following the injury, which also negatively impacts HRQOL [11]. When HRQOL domains and coping are interrupted by a TBI, the ability to understand limitations and adjust behaviors, known as emotional regulation, may decline.

This ability to regulate emotions by managing behaviors and making adaptations in social contexts $[12,13]$ is important to consider in a TBI-specific population. Given that TBI can affect 
both psychological (cognitive) and social HRQOL domains, individuals post-TBI are likely to benefit from interventions that directly address emotional regulation [14]. Additionally, emotional regulation can act as a predictor of HRQOL outcomes. Regarding individuals affected by TBI, Henry et al. [15] found that participants with TBI, as compared to controls, had significant difficulty identifying and describing emotions [15]. This identification of emotions can be important to aspects of daily function [16]. Emotions, such as hope and optimism, have been linked to higher scores in HRQOL [17]. In general, the ability to cultivate positive emotions may be fundamental to well-being [18], and may be particularly important following a TBI if an individual's emotional regulation capabilities are disrupted [13].

Negative changes in post-TBI HRQOL and emotional regulation indicate a need for interventional research that can address these important outcomes $[13,7]$. TBI creates a perceived mind-body disconnect for many individuals [19]. A study by Fernros and Furnhoff (2008) analyzed HRQOL changes following one week of mind-body activities and found significant improvements in the subsets of general health perception, and emotional well-being [20]. Therefore, interventions focused on connecting the mind and body may improve the emotional domain of HRQOL and should be further studied for individuals with TBI in conjunction with emotional regulation. Participants with stroke, another neuropathology, reported an increased sense of connection and specifically noted improvements in psychological, physical and emotional domains following a yoga intervention [21]. As a mind-body practice focused on physical postures and mental awareness, yoga can lend itself to a neurological population when implemented by trained practitioners [22]. Currently, there are a limited number of TBI specific yoga studies targeting HRQOL and none targeting emotional regulation. Silverthorne et al, completed the only TBI-specific yoga study that showed significant improvements in physical functioning and emotional well-being from baseline to nine months following the intervention [23]. In another related population, researchers evaluated an 8-week yoga program for acquired brain injury [24]. They found that the yoga intervention group had significant improvements in HRQOL, and participants reported high satisfaction ratings indicating that yoga is potentially feasible for individuals with brain injuries. Other studies examined the effects of mindfulness-based stress reduction (MBSR) for individuals after TBI $[25,26]$, and MBSR programs contain a Hatha yoga element but are not designed to be yoga interventions [27]. There is however more yogaspecific research available regarding other clinical populations (non-TBI). For example, the physical or HRQOL benefits related to yoga interventions have been demonstrated in other clinical neurological populations [28], such as: multiple sclerosis [29]; Parkinson disease [30-32]; and stroke [33,21]. Yet, there is currently no research specifically assessing improvements in emotional regulation and HRQOL after yoga for individuals with TBI. Many studies recommend that future research should examine the role of yoga, or other non-pharmaceutical treatment, for individuals with TBI $[34,35]$. The purpose of this study was to analyze the participant reported outcomes of emotional regulation and HRQOL, along with their perceptions of an eight- week yoga intervention.

\section{Methods}

\section{Design}

This was a multi-methods case-study including three participants and was focused on changes in HRQOL and emotional regulation following a yoga intervention. Each participant completed 16 sessions of yoga, twice a week for eight weeks, and outcome data were collected before and after the eight-week yoga intervention.

\section{Participants}

All participants were adults, 18 years of age or older, and consented to the study following Institutional Review Board approval. Study participants were classified as having a chronic TBI (greater than six months post injury). All participants received occupational therapy or physical therapy services postTBI, but had completed all TBI rehabilitation prior to enrollment in this study. In order to qualify for the study, individuals had to score $\geq 4$ / 6 on the Short Mini Mental Status Exam (MMSE)[36], be able to speak, read, and understand English and be able to stand with or without an assistive device.

\section{Data collection}

Demographic data, patient reported outcome data, and qualitative data were collected by a trained research assistant. Age, race, gender, marital/partnership status, and education were all included as demographic data. Date of TBI, years since TBI, and corresponding hemiparesis were also collected. Quantitative assessments occurred before and after the yoga intervention through use of the DERS and QOLIBRI.

\section{Quantitative data collection-Difficulty in Emotion Regulation Scale (DERS)}

The DERS is a 36 -item questionnaire, consisting of options 1 "almostnever" to 5 "almostalways" [37]. Six subscales are included: lack of emotional awareness; lack of emotional clarity; nonacceptance of negative emotions; lack of strategy building; lack of control of impulsive behaviors; and inability to behave during goal-directed emotions while experiencing negative emotions. There are no established cut-off scores for TBI participants when using the DERS. In this study, items were reverse scored which made a higher total DERS score indicate higher emotional regulation abilities.

\section{Quantitative data collection-Quality of Life after Brain Injury (QOLIBRI)}

The QOLIBRI is a 37-item questionnaire that includes a 5-point Likert scale with scoring from 1 "not at all satisfied" to 5 "very satisfied" [38]. Part one measures satisfaction level regarding cognition, feelings and emotions, autonomy and daily life, and social relationships. Part two focuses on impact, in regard to negative feelings and restrictions. The total score $0-100$ acts as a HRQOL measurement for individuals following TBI, with higher scores indicating better HRQOL [39]. 


\section{Qualitative data collection}

Qualitative data were collected post intervention using an 18 question face-to-face semi-structured interview format. All interviews were audio recorded for verbatim transcription. Primary questions included, "What has been your overall experience in the therapy program?" and "What did you expect the yoga program to be like before it started?" Further questions were developed as the interview progressed, and when appropriate participants were probed for further information with phrases like, "expand on that thought."

\section{Intervention}

The intervention consisted of one-hour yoga sessions, provided by a registered yoga therapist (RYT), bi-weekly for eight weeks. Yoga was delivered in a 1:1 fashion and a research assistant was available if needed to assist with postures or moving to and from the floor. The protocol included postures advancing from seated, to standing, then supine, or quadruped on the floor, with the constant option for adjustment per participant and safety needs. Sessions began with breathing techniques to enable awareness. Adjustments throughout the session included posture modifications or the addition of a yoga strap or block for support and ideal biomechanical alignment. Sessions ended with ten minutes of progressive muscle relaxation alongside guided meditation, with the RYT providing eye pillows while participants were supine on their yoga mats. See Table 1 for a full description of yoga postures and progression. Additionally, information on the protocol has been previously published focusing on the physical and balance outcomes [40].

Table 1: Yoga intervention.

\begin{tabular}{|c|c|c|}
\hline $\begin{array}{l}\text { Position (Week } \\
\text { Estimate) }\end{array}$ & Description & $\begin{array}{l}\text { Yoga Practice: } \\
\text { Select Examples }\end{array}$ \\
\hline Seated (Weeks 1-8) & $\begin{array}{l}\text { Opening breathing } \\
\text { Breathing Practices: } \\
\text { i. } \text { Breath with sound } \\
\text { ii. Natural rate breathing } \\
\text { iii. Prolonged exhale breathing } \\
\text { iv. Alternate nostril breathing } \\
\text { Eye Movements, eyes opened or closed: } \\
\text { i. Diagonal } \\
\text { ii. Horizontal } \\
\text { iii. } \text { Circles } \\
\text { iv. Hourglass } \\
\text { Cervical Movements: } \\
\text { i. Rotations } \\
\text { ii. Lateral flexion } \\
\text { Head Movements: } \\
\text { i. } \quad \text { Mandible flexion and extension } \\
\text { i. Shoulder Movements: } \\
\text { ii. Shoulder shrugs } \\
\text { iii. Shoulder forward rolls } \\
\text { iv. Shoulder backward rolls } \\
\text { v. } \quad \text { Sotations with shoulders in abducted position } \\
\text { Torso Movements: } \\
\text { i. Side flexion } \\
\text { ii. } \text { Rotation }\end{array}$ & $\begin{array}{l}\text { Breathing: } \\
\text { a. Ujjayi } \\
\text { b. Pranayama } \\
\text { c. Nadi Shodhana } \\
\text { Eye Movements: } \\
\text { a. Drishti Bheda } \\
\text { b. Pralokita, Saachi, Alokita } \\
\text { Head/Neck/Torso Movements: } \\
\text { i. Adapted Ardha Chandrasana } \\
\text { ii. Adapted Simhasana } \\
\text { iii. Ardha Matsyendrasana }\end{array}$ \\
\hline $\begin{array}{c}\text { Standing } \\
\text { (Weeks 3-8) }\end{array}$ & 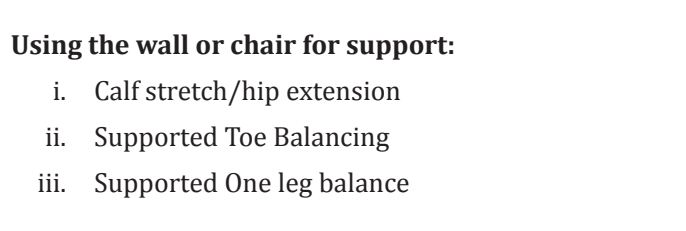 & $\begin{array}{l}\text { Standing Movements: } \\
\begin{aligned} \text { i. } & \text { Tadasana } \\
\text { ii. } & \text { Virasan } \\
\text { iii. } & \text { Utkatasana } \\
\text { iv. } & \text { Vrksasana }\end{aligned}\end{array}$ \\
\hline
\end{tabular}




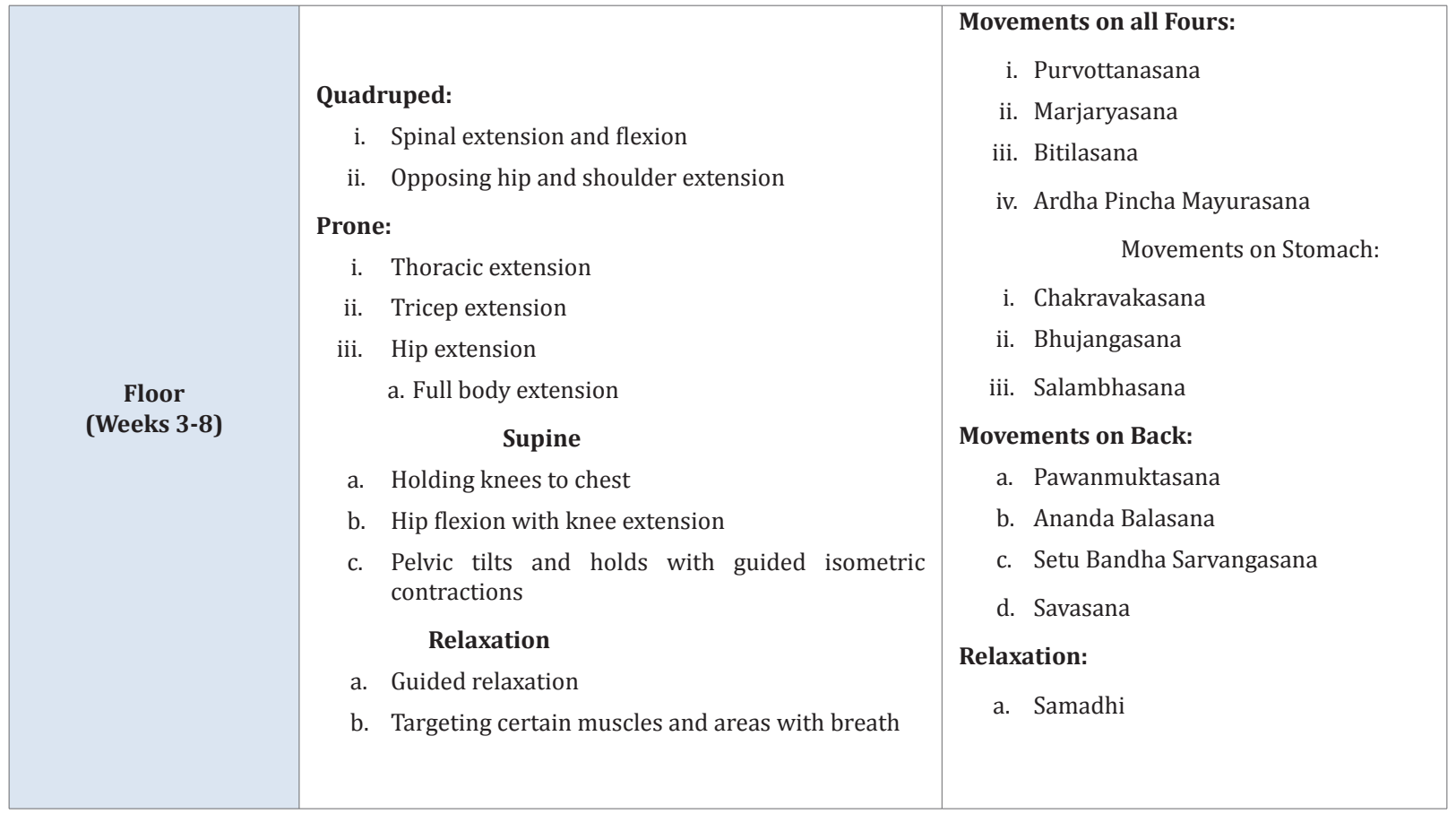

\section{Data Analysis}

\section{Quantitative data}

Quantitative data were analyzed using SPSS 20.0 (Chicago, IL). Demographic data were described using descriptive statistics: means and standard deviations or frequencies and proportions. Pre and posttest means and standard deviations are included for the DERS and QOLIBRI scores. With the case study format of three participants, researchers calculated a percent change for each outcome measure (Posttest-Pretest/Pretest x100).

\section{Qualitative data}

Transcripts were transcribed verbatim by a trained research assistant into a word processing document and then were imported into NVivo for analyses (NVivo 10 QSR International, Victoria, Australia). Transcripts for qualitative data were analyzed and coded by two trained researchers. Two primary themes were identified a priori based on the purpose of these analyses and therefore focused on the variables of interest: HRQOL and emotional regulation. Secondary themes then evolved with multiple researchers through an iterative consensus building process. Through this process, researchers agreed upon reoccurring subthemes which emerged during analysis of semistructured interviews (Figure 1). Researchers then used NVivo software to code each theme identified for qualitative analysis and comparison. Qualitative comments that best illustrate each code or theme are included in the results.

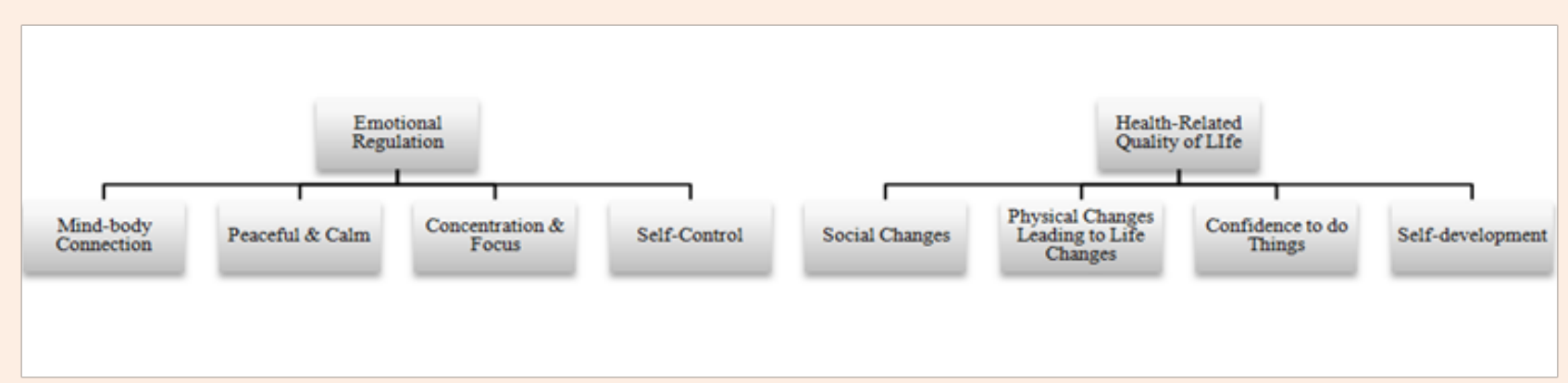

Figure 1: Primary and Secondary Themes derived from Participant Interviews.

\section{Results}

\section{Demographics}

Three individuals enrolled and completed the yoga intervention. Two were female, two were more than ten years post TBI, and one was married. See Table 2 for additional demographic and TBI characteristics. 
Table 2: Demographic Information.

\begin{tabular}{|c|c|c|c|c|}
\hline Variable & Participant One & Participant Two & Participant Three & $\begin{array}{c}\text { Mean } \\
n=3\end{array}$ \\
\hline Age & 42 & 48 & 43 & $44.33 \pm 3.22$ \\
\hline Gender & Female & Female & Male & Two female $(67 \%)$ \\
\hline Race & White & 'Other' & White & Two white $(67 \%)$ \\
\hline Years since TBI & 21 & 28 & 9 & $19.33 \pm 9.6$ \\
\hline Corresponding hemiparesis & Yes & Yes & Yes & Hemiparetic (100\%) \\
\hline Age at time of injury (years) & 22 & 21 & 35 & $26 \pm 7.81$ \\
\hline Medication for anxiety (current) & No & No & Yes & No \\
\hline $\begin{array}{l}\text { Medication for depression } \\
\text { (current) }\end{array}$ & Yes & No & Yes & Yes \\
\hline Partner & Single & Widowed & Married & \\
\hline Education (any college) & Post-graduate & Some college & Some college & Some college $(100 \%)$ \\
\hline
\end{tabular}

\section{Quantitative data}

DERS scores indicated overall improvements, the mean DERS score improved from 94.67 to 109.67, a 16\% improvement. Two out of three participants presented higher scores indicating improved emotional regulation capabilities (Table 3). Participant three showed the largest change, with an increase of $36 \%$ following the yoga intervention.

QOLIBRI scores improved for all three participants following the intervention (Table 3). Individually, scores increased from between $5 \%$ and $8 \%$, showing an improved perceived HRQOL. The overall mean score increased from 108.33 to 115.33, which is a $6 \%$ positive change. Further analysis was then obtained using semi-structured interviews.

Table 3: Emotional Regulation and Health-Related Quality of Life Changes.

\begin{tabular}{|c|c|c|c|c|}
\hline Outcome Measure & $n=3$ & $\begin{array}{l}\text { Baseline } \\
\text { Score }\end{array}$ & $\begin{array}{l}8 \text { weeks } \\
\text { Score }\end{array}$ & $\%$ Change \\
\hline \multirow{4}{*}{ Difficulty in Emotional Regulation Scale } & Participant 1 & 82 & 80 & $-2 \%$ \\
\hline & Participant 2 & 118 & 135 & $14 \%$ \\
\hline & Participant 3 & 84 & 114 & $36 \%$ \\
\hline & Mean (SD) & $94.67 \pm 20.23$ & $109.67 \pm 27.75$ & $16 \%$ \\
\hline \multirow{4}{*}{ Quality of Life After Brain Injury } & Participant 1 & 133 & 144 & $8 \%$ \\
\hline & Participant 2 & 84 & 89 & $6 \%$ \\
\hline & Participant 3 & 108 & 113 & $5 \%$ \\
\hline & Mean (SD) & $108.33 \pm 24.50$ & $115.33 \pm 27.57$ & $6 \%$ \\
\hline
\end{tabular}

\section{Emotional regulation qualitative data}

Driven by the research questions, two primary themes were identified from the variables of interest: emotional regulation and HRQOL. Secondary themes were then identified through examination and analysis of the semi-structured interviews. Secondary themes within emotional regulation included: MindBody Connection; Peaceful \& Calm; Concentration \& Focus; and Self-Control (Figure 1). The data showed an improvement in overall self-perceived ability to regulate or manage emotions. Certain quotes from the data have been previously published in a manuscript on the physical effects of yoga for chronic TBI [40].
A few of these quotes bear repeating due to the powerful nature of the content of the data, and relation specifically to the research questions.

\section{Mind-body connection}

Two participants acknowledged how yoga practice facilitated a stronger relationship between the mind and body. Participant One specifically noted the benefits of yoga to individuals with chronic TBI, he stated "I mean mine's what? 19 years, 20 years after, and I'm noticing different things that...are improving. I mean I think that it would be incredibly valuable to someone with [a] brain injury that was just because of the connection." Participant Two 
also noted the connection and simply stated, "I am more mindful". Whether noting individual changes, or beneficial changes for others with chronic TBI, an increased connection between mind and body surfaced from the interviews.

\section{Peaceful \& calm}

Two participants identified peaceful and calm thoughts related to emotional regulation. One participant commented on how increased peacefulness during or after yoga had led to calmer feelings throughout daily activities, "It's more real now...I feel more peaceful." When asked about the first week of yoga, that participant stated, "it was very peaceful." Another participant noted his control in the way of revving up or relaxing: "The breathing techniques were huge... [In] how to calm myself down or how to ram [rev] myself up." Attention to breath had provided an opportunity to elicit a peaceful awareness.

\section{Concentration \& focus}

Cognition may be impacted post-TBI, in this study concentration and focus emerged as a noted improvement from yoga by two of the participants. For example, Participant Three compared previous post-TBI treatments and noted how this yoga intervention finally addressed the ability to "now be able to concentrate," in a way that he had not previously seen improvements, despite specialized TBI interventions. Expanding on the concentration piece, he noted that his attention was more focused on his kids at tee ball and he did "not constantly scan the crowds or you know all the people around it's just there's so many things that just made my life better." Contextually, his statement was in regard to not needing to scan the crowds for terrorists or harm, given he is a veteran with a brain injury, post-traumatic stress, and multiple physical injuries.

\section{Self-control}

Another theme which emerged under emotional regulation was self-control. Participant Two did not experience an improvement in DERS scores but described her overall improvement in selfcontrol, stating that for her the yoga intervention was "more mental" with a focus on "getting more self-control." Participant Three, the veteran, discussed using the breathing techniques and eye movements learned in the program as a method of selfcontrol "to ground you in the here and now," and as an escape from continuing to perceive the threats of Iraq in his home, while driving, and elsewhere in his day to day life. He discussed these improvements through daily activities, as well as within an overarching sense of self-control that he received from the yoga intervention.

\section{Health-related quality of life qualitative data}

HRQOL was a qualitative primary theme and included the following secondary themes: Social Changes; Physical Changes Leading to Life Changes; Confidence to do Things; and SelfDevelopment (Figure 1).

\section{Social changes}

Relating to HRQOL, all participants described an increase in social engagement as the result of this yoga intervention. One participant discussed how social changes had been significantly impacted in the form of "wanting to go out more and to have that confidence to be able to go out and do it." Increased socialization and engagement due to the yoga intervention emerged as a theme from all three participants.

\section{Physical changes leading to life changes}

Participants also identified how physical changes resulting from yoga practice became a vehicle to complete their chosen meaningful activities. Participant One expressed that halfway through the intervention he was engaging in an occupation he had been missing, "I started playing golf...last September - and so probably five weeks into yoga I went out for the first time this year. It was only the second time I'd ever played a full-size course [since my injury]." Participant Two similarly discussed the impact of physical improvements and stated: "I learned...that I could make my body move and accomplish feats that I didn't think were possible." Due to the yoga intervention Participant Three highlighted the daily improvements related to strength, "I've got more strength in my legs and I've got more stamina now...to be able to go out."

\section{Confidence to do things}

People who have experienced TBI often report dissatisfaction in their self-esteem levels, which influence many pieces of performance in life [41]. Two out of three participants indicated that confidence since the time of injury had been a limiting factor, and improvements in confidence occurred during the yoga intervention. This improvement allowed them to complete more desired activities. For example, one participant noted the increased confidence in the form of future goals, "I really want to go back to school and start and complete my degree."

\section{Self-development}

The semi-structured interview revealed statements from all three participants regarding personal growth. One participant noted yoga as a form of self-development, and indicated "I used it more...to...develop myself, that's what I appreciate more, the selfdevelopment." While another participant stated, "I'm not quite as hard on myself," in response to how life was different following the program.

\section{Interaction of multiple HRQOL themes}

Participant Three importantly identifies the holistic relationship in HRQOL: "I mean it's rocked my world. It's changed my life. I mean all the different aspects." For him, all the HRQOL changes culminated in perceived new capability in his role as a father: "this has changed my world and given me a new life back, because I've got a new opportunity now with my two youngest sons to be the Dad that I couldn't be, in my eyes, to my older kids." He further commented on several HRQOL domains "physically, emotionally, mentally...it's given me, you know, my life back. It's opened up so many doors for me."

\section{Discussion}

These data indicated that an eight-week yoga intervention for 
people with TBI is potentially an impactful modality to address HRQOL and emotional regulation. The three individuals included in this multi-methods study showed an overall improvement in QOLIBRI and DERS scores, as well as perceived improvements as evidenced by the semi-structured interviews. The QOLIBRI provided a foundation for HRQOL domain analysis, and the data from the DERS elaborated on the "emotions" domain through quantification of emotional regulation. For example, the QOLIBRI assesses emotions, but also includes the additional domains: cognition, general "self", daily life and autonomy, social relationships, and physical problems [14]. Emotion was then further explored with the DERS through six subsets assessing emotional regulation: “(a) lack of awareness of emotional responses; (b) lack of clarity of emotional responses; (c) nonacceptance of emotional responses, (d) limited access to emotion regulation strategies perceived as effective, (e) difficulties controlling impulses when experiencing negative emotions, and (f) difficulties engaging in goal-directed behaviors when experiencing negative emotions" [37]. This three-person format then allowed for in-depth discussion and understanding of each domain through analyses of semi-structured interviews. Researchers focused on the participants' perspectives and identified potential changes related to HRQOL and emotional regulation for the three participants.

\section{Emotional regulation}

Emotional regulation can be viewed as the constant situational adaptation of behaviors to meet social expectations. This study separated four subsets of emotional regulation that emerged in qualitative interviews: mind-body connection, peaceful \& calm, concentration \& focus, and self-control. Yoga interventions frequently include attention to mindfulness, or moment-tomoment awareness through the development of adaptive techniques to face difficult situations [42], which is a part of emotional regulation. Azulay and Mott (2016) implemented a Mindfulness Attention Program and indicated significant improvements in DERS scores for individuals with mixed brain injuries [43]. Mindfulness programs may target the disconnect between the mind and body, which is a common theme for individuals with neurological impairments $[44,19]$. The current study presented qualitative data which described an increased mind-body connection for three participants following a yoga intervention.

Further, previous research indicates that yoga can trigger the ability to implement a relaxation response $[45,46]$, this supports the presented qualitative results regarding increased peaceful and calm feelings. A study done with individuals diagnosed with multiple sclerosis assessed emotional regulation and found that higher emotional regulation correlated to improved scores in psychological and environmental QOL domains [47]. Participants in the current study highlighted HRQOL domains that were affected in conjunction with emotional regulation changes. In a different study, researchers used the DERS measure and found that, in 50 participants with TBI, global distress strongly related to lower DERS scores [48]. High negative correlation between emotional regulation and global distress calls for methods specifically addressing emotional regulation. Furthermore, continuous emotional regulation can lead to higher life satisfaction [49], reasoning that emotional regulation and quality of life cannot be disentangled, and measurement together is cornerstone to future treatment planning for individuals with neurological impairments. Collectively, these data represent preliminary case study evidence for an individualized yoga intervention and support further exploration of yoga as a treatment intervention post-TBI.

\section{Health-related quality of life}

Increased difficulty in emotional regulation has been correlated to decreased ability to sustain meaningful relationships, which leads to a reduction in overall quality of life [15]. This study divided HRQOL into four subsets that emerged during qualitative analysis of the interviews: social change, physical changes leading to life changes, confidence to do things, and self-development. Paralleling the current findings relating to social change, a study by Hawthorne, Gruen, \& Kaye (2009) found that lower HRQOL is associated with decreased social interactions [50]. Individuals with TBI generally report lower HRQOL [50]. All three participants in this study discussed their increased social participation following the yoga intervention, which was supported by increased HRQOL through their QOLIBRI scores. Related findings were seen in a yoga study for healthy older adults; those who participated in yoga rated HRQOL and social functioning significantly higher than the control or exercise groups [51]. Improvements in social engagement may potentially be related to increase varying categorical developments, for example balance self-confidence, following a yoga intervention.

Regular yoga practice has been connected to increased confidence [52]. Two participants in this study discussed their increased confidence, often in relation to returning to activities they had avoided since their TBI. In a mindfulness study for a population with mixed (ex. anoxic, traumatic) brain injury, improvements were seen in perceived self-efficacy and perceived QOL measures, emphasizing the connection between confidence and well-being through mindfulness [43]. Another part of increased confidence, in the current study, could be attributed to self-reported physical improvements, which allowed for a return to participation. The relationship between physical changes, confidence, and stroke-specific QOL is highlighted in another eight-week yoga intervention study, which revealed increased balance self-efficacy and quality of life outcomes for individuals with chronic stroke [53]. The results can be interpreted to show a relationship between the physical component of balance, the perceptual impact of confidence, and resulting overall HRQOL improvements. All three participants in this current study discussed how physical changes had promoted increased life involvement. Participant One, for example, returned to his meaningful activity of golfing on a full-size course halfway through the yoga intervention. Silverthorne et al. (2012) implemented breath-focused yoga, for individuals with severe TBI, and found significant improvements in physical function, emotional wellbeing, and overall health [23]. Tying together the important factors included in emotional regulation helps to perhaps explain some of the improvements seen throughout HRQOL in this study. 


\section{Limitations}

Limitations in this study include that there was no control group and a small sample size, which is common in emerging mind-body intervention research and continues to be a limitation especially in neurological populations [22]. The size makes it difficult to generalize the results to other individuals with chronic TBI, however the small case study was an important first step in this line of research. In addition, severity of impairment (mild, moderate, severe) and the location of the injury were not included in the demographic data. Therefore, researchers analyzing these data cannot discuss changes following yoga as they relate to specific TBI categorical classifications.

\section{Strengths and implications for future research}

Future research could include categorical classifications of TBI. Utilizing these classifications would allow for further comparisons between groups, to determine the best fit or timing for yoga interventions. This study highlights an intervention strategy that improved emotional regulation and HRQOL scores for individuals with TBI. To generalize the results and prove efficacy, a larger sample size and control comparisons are needed. When considering the benefits of larger sample sizes, it is also important to consider the strengths of a small yoga group. In this study, participants were provided individualized adaptations and adjustments throughout yoga sessions, tailoring each session to meet the participants' needs. Hands-on adaptation and attention to each participant could have been a reason for the positive results seen in HRQOL and emotional regulation. However, a group yoga intervention for people with TBI should be tested to meet social and economic needs.

\section{Conclusion}

This study provides preliminary evidence that an eight-week yoga program is a beneficial option to simultaneously improve emotional regulation and HRQOL for individuals with chronic TBI. Improvements were seen with this sample, and this study highlights the importance of assessing emotional regulation along with HRQOL for individuals with TBI. However, further research is warranted because this study was not large enough to be generalizable.

\section{Acknowledgments}

Dr. Schmid and this study were supported by a Veterans Administration Career Development Award (VA RR\&D CDA D6174W). We thank Nancy Schalk, a yoga therapist, for developing and teaching the yoga intervention to each of the study participants. We also thank the Indiana University Occupational Therapy students involved with this research: Erin DebaunSprague, MS OTR; Elizabeth Short, MS OTR; Jenna Mitchell, MS OTR; Laura Montgomery, MS OTR; and Tiffani Davis, MS OTR.

\section{References}

1. https://www.ninds.nih.gov/Disorders/Patient-CaregiverEducation/Hope-Through-Research/Traumatic-Brain-Injury-HopeThrough
2. http://www.cdc.gov/traumaticbraininjury/get_the_facts.html

3. Zaloshnja E, Miller T, Langlois JA, Selassie AW (2008) Prevalence of Long-Term Disability From Traumatic Brain Injin the Civilian Population of the United States, 2005. J Head Trauma Rehabil 23(6): 394-400.

4. Corrigan JD, Selassie AW, Orman JA (2010) The epidemiology of traumatic brain injury. J Head Trauma Rehabil 25(2): 72-80.

5. Whiteneck GG, Cuthbert JP, Corrigan JD, Bogner JA (2016) Prevalence of self-reported lifetime history of traumatic Brain Injand associated disability: a statewide population-based survey. The J Head Trauma Rehabil 31(1): E55-E62.

6. Corrigan JD, Cuthbert JP, Harrison-Felix C, Whiteneck GG, Bell JM, et al. (2014) US population estimates of health and social outcomes 5 years after rehabilitation for traumatic brain injury. The J Head Trauma Rehabil 29(6): E1-E9.

7. von Steinbuechel N, Richter S, Morawetz C, Riemsma R (2005) Assessment of subjective health and health-related quality of life in persons with acquired or degenerative brain injury. Curr Opin Neurol 18(6): 681-691.

8. Annemieke Scholten (2016) Outcome after Traumatic Brain Injury: Epidemiology, impact and assessment. Erasmus Medical Center.

9. McCarthy ML1, MacKenzie EJ, Durbin DR, Aitken ME, Jaffe KM, et al. (2006) Health-related quality of life during the first year after traumatic brain injury. Archives of pediatrics \& adolescent medicine 160(3): 252-260.

10. Health-Related Quality of Life and Well-Being (2014).

11. Sasse N, Gibbons H, Wilson L, Martinez R, Sehmisch S, et al. (2014) Coping strategies in individuals after traumatic brain injury: associations with health-related quality of life. Disabil Rehabil 36(25): 2152-2160.

12. Koole SL (2009) The psychology of emotion regulation: An integrative review. Cognition and emotion 23(1): 4-41.

13. Cattran C1, Oddy M, Wood R (2011) The development of a measure of emotional regulation following acquired brain injury. J Clin Exp Neuropsychol 33(6): 672-679.

14. von Steinbüchel N, Wilson L, Gibbons H, Hawthorne G, Höfer S, et al. (2010) Quality of Life after Brain Inj(QOLIBRI): scale validity and correlates of quality of life. J Neurotrauma 27(7): 1157-1166.

15. Henry JD1, Phillips LH, Crawford JR, Theodorou G, Summers F (2006) Cognitive and psychosocial correlates of alexithymia following traumatic brain injury. Neuropsychologia 44(1): 62-72.

16. Kipps CM, Mioshi E, Hodges JR (2009) Emotion, social functioning and activities of daily living in frontotemporal dementia. Neurocase 15(3): 182-189.

17. Sivan Maoz, Harif I, Magen, H (2016) Relationship Between Positive Personality Traits and Rehabilitation Outcomes Following Acquired Brain InjSeveral Years Post-Injury. Archives of Physical Medicine and Rehabilitation 97(10): e26.

18. Fredrickson B L (2000) Cultivating positive emotions to optimize health and well-being. Prevention \& Treatment 3(1): 1-25.

19. Levack WM, Kayes NM, Fadyl JK (2010) Experience of recovery and outcome following traumatic brain injury: a metasynthesis of qualitative research. Disabil Rehabil 32(12): 986-999. 
20. Fernros L, Furhoff AK, Wändell PE (2008) Improving quality of life using compound mind-body therapies: evaluation of a course intervention with body movement and breath therapy, guided imagery, chakra experiencing and mindfulness meditation. Qual Life Res 17(3): 367-376.

21. Garrett R, Immink MA, Hillier S (2011) Becoming connected: the lived experience of yoga participation after stroke. [Research Support, Non-U.S. Gov't]. Disabil Rehabil 33(25-26): 2404-2415.

22. Wahbeh H, Elsas SM, Oken BS (2008) Mind-body interventions applications in neurology. Neurology 70(24): 2321-2328.

23. Silverthorne C, Khalsa SB, Gueth R, DeAvilla N, Pansini J (2012) Respiratory, physical, and psychological benefits of breath-focused yoga for adults with severe traumatic Brain Inj(TBI): a brief pilot study report. Int J Yoga Therap 22(1): 47-51.

24. Donnelly KZ, Linnea K, Grant DA, Lichtenstein J (2017) The feasibility and impact of a yoga pilot programme on the quality-of-life of adults with acquired brain injury. Brain Inj 31(2): 208-214.

25. Johansson, Bjuhr H, Rönnbäck L (2012) Mindfulness-based stress reduction (MBSR) improves long-term mental fatigue after stroke or traumatic brain injury. Brain Inj 26(13-14): 1621-1628.

26. Azulay J, Smart CM, Mott T, Cicerone KD (2013) A pilot study examining the effect of mindfulness-based stress reduction on symptoms of chronic mild traumatic brain injury/postconcussive syndrome. The J Head Trauma Rehabil 28(4): 323-331.

27. Cullen M (2011) Mindfulness-based interventions: An emerging phenomenon. Mindfulness 2(3): 186-193.

28. Patel NK, Newstead AH, Ferrer RL (2012) The effects of yoga on physical functioning and health related quality of life in older adults: a systematic review and meta-analysis. J Altern Complement Med 18(10): 902-917.

29. Ahmadi A, Nikbakh M, Arastoo A, Habibi AH (2010) The effects of a yoga intervention on balance, speed and endurance of walking, fatigue and quality of life in people with multiple sclerosis. Journal of Human Kinetics 23: 71-78.

30. Mendoza EU, Van Puymbroeck M, Walter A, Hawkins BL, Woschkolup $\mathrm{K}$, et al. (2016) Effectiveness of Yoga in Decreasing Symptoms and Improving Quality of Life in Parkinson's Disease. Archives of Physical Medicine and Rehabilitation 97(10): e63-e64.

31. Sharma NK, Robbins K, Wagner K, Colgrove YM (2015) A randomized controlled pilot study of the therapeutic effects of yoga in people with Parkinson's disease. Int J Yoga 8(1): 74.

32. Van Puymbroeck M, Walter A, Hawkins B, Woschkolup K, UrreaMendoza E, et al. (2016) Functional Improvements in Parkinson's Disease Following Therapeutic Yoga. Archives of Physical Medicine and Rehabilitation 97(10): e5.

33. Schmid AA, Miller KK, Van Puymbroeck M (2015) Yoga After Stroke Leads to Improvements in Multiple Domains of Quality of Life. Archives of Physical Medicine and Rehabilitation 10(96): e93.

34. Patil VK, St Andre JR, Crisan E, Smith BM, Evans CT, et al. (2011) Prevalence and treatment of headaches in veterans with mild traumatic brain injury. Headache: Headache 51(7): 1112-1121.

35. Hernández TD, Brenner LA, Walter KH, Bormann JE, Johansson B (2016) Complementary and alternative medicine (CAM) following traumatic Brain Inj(TBI): Opportunities and challenges. Brain Res 1640: 139-151
36. Callahan CM, Unverzagt FW, Hui SL, Perkins AJ, Hendrie HC (2002) Six-item screener to identify cognitive impairment among potential subjects for clinical research. Med Care 40(9): 771-781.

37. Neumann A, van Lier PA, Gratz KL, Koot HM (2004) Multidimensional assessment of emotion regulation and dysregulation: Development, factor structure, and initial validation of the difficulties in emotion regulation scale. Assessment 17(1): 138-149.

38. von Steinbüchel N, Wilson L, Gibbons H, Hawthorne G, Höfer S, et al. (2010) Quality of Life after Brain Inj(QOLIBRI): scale development and metric properties. J Neurotrauma 27(7): 1167-1185.

39. Truelle JL, Koskinen S, Hawthorne G, Sarajuuri J, Formisano R, et al. (2010) Quality of life after traumatic brain injury: the clinical use of the QOLIBRI, a novel disease-specific instrument. Brain Inj 24(11): $1272-1291$.

40. Schmid AA1, Miller KK, Van Puymbroeck M, Schalk N (2016) Feasibility and results of a case study of yoga to improve physical functioning in people with chronic traumatic brain injury. Disabil Rehabil 38(9): 914-920.

41. Mailhan L, Azouvi P, Dazord A (2005) Life satisfaction and disability after severe traumatic brain injury. Brain Inj 19(4): 227-238.

42. Nagarathna R, Nagendra H, Monro R (1990) Yoga for common ailments: Gaia Books Limited.

43. Azulay J, Mott T (2016) Using Mindfulness Attention Meditation (MAP) with a Mixed Brain Inj Population to Enhance Awareness and Improve Emotional Regulation. Journal of Psychology and Clinical Psychiatry 6(5): 00372.

44. Ellis-Hill CS, Payne S, Ward C (2000) Self-body split: issues of identity in physical recovery following a stroke. Disabil Rehabil 22(16): 725733.

45. Arambula P, Peper E, Kawakami M, Gibney KH (2001) The physiological correlates of Kundalini Yoga meditation: a study of a yoga master. Appl Psychophysiol Biofeedback 26(2): 147-153.

46. Arora S, Bhattacharjee J (2008) Modulation of immune responses in stress by Yoga. Int J Yoga 1(2): 45-55.

47. Phillips LH, Saldias A, McCarrey A, Henry JD, Scott C, et al. (2009) Attentional lapses, emotional regulation and quality of life in multiple sclerosis. Br J Clin Psychol 48(1): 101-106.

48. Shields C, Ownsworth T, O’Donovan A, Fleming J (2016) A transdiagnostic investigation of emotional distress after traumatic brain injury. Neuropsychol Rehabil 26(3): 410-445.

49. Gross JJ, John OP (2003) Individual differences in two emotion regulation processes: implications for affect, relationships, and wellbeing. J Pers Soc Psychol 85(2): 348.

50. Hawthorne G, Gruen RL, Kaye A H (2009) Traumatic Brain Injand long-term quality of life: findings from an Australian study. J Neurotrauma 26(10): 1623-1633.

51. Oken BS, Zajdel D, Kishiyama S, Flegal K, Dehen C, et al. (2006) Randomized, controlled, six-month trial of yoga in healthy seniors: effects on cognition and quality of life. Altern Ther Health Med 12(1): 40.

52. Woodyard C (2011) Exploring the therapeutic effects of yoga and its ability to increase quality of life. Int J Yoga 4(2): 49.

53. Schmid AA, Van Puymbroeck M, Altenburger PA, Schalk NL, Dierks TA, et al. (2012) Poststroke balance improves with yoga: a pilot study. Stroke 43(9): 2402-2407. 